\title{
Removal of a giant gastric bezoar with the grasp-and-smash technique through a double-channel endoscope
}

A 78-year-old woman who had a longterm habit of eating persimmons and had received treatment to soften a gastric bezoar with Coca-Cola at another hospital for about half a year was admitted to our Emergency Unit due to hematemesis. The patient underwent an upper gastroscopy (GIF-Q260); Olympus, Tokyo, Japan), which demonstrated a gastric ulcer with exposed vessels in the angular region and a giant ellipsoidshaped bezoar with hard surface occupying over half of the gastric lumen (\Fig.1a, \Fig.1b). 10 days after endoscopic hemostasis for hemorrhagic ulcer, we tried to remove the bezoar with the grasp-and-smash technique through a double-channel endoscope. (GIF-2T240; Olympus, Tokyo, Japan) (\Fig.1c, > Fig.1d, > Fig. 1e, > Fig. 1f, > Video 1). First, we inserted a snare with a 33-mm loop (Dualoop; Medico's Hirata, Osaka, Japan) from one channel and grasped the short axis of the bezoar, which was too hard to break in two by using a snare alone. Next, an alligator forceps (FG-47L1; Olympus Tokyo, Japan) was inserted from another channel. We smashed the bezoar many times with a forceps while pulling the snare toward ourselves. With this strategy, the force for smashing with a forceps was easily transmitted to the bezoar even if its surface was hard and slippery. The procedure of breaking the bezoar into small pieces took approximately 30 minutes and caused no adverse events. After that, all pieces of the bezoar were collected with a retrieval net (Roth Net; Olympus, Tokyo, Japan) through a flexible guide tube (Flexible Overtube.; Sumitomo Bakelite, Tokyo, Japan).

Recently, endoscopic treatments including the use of lithotripters, specific bezoaratom kits $[1,2]$, electrosurgical kni-
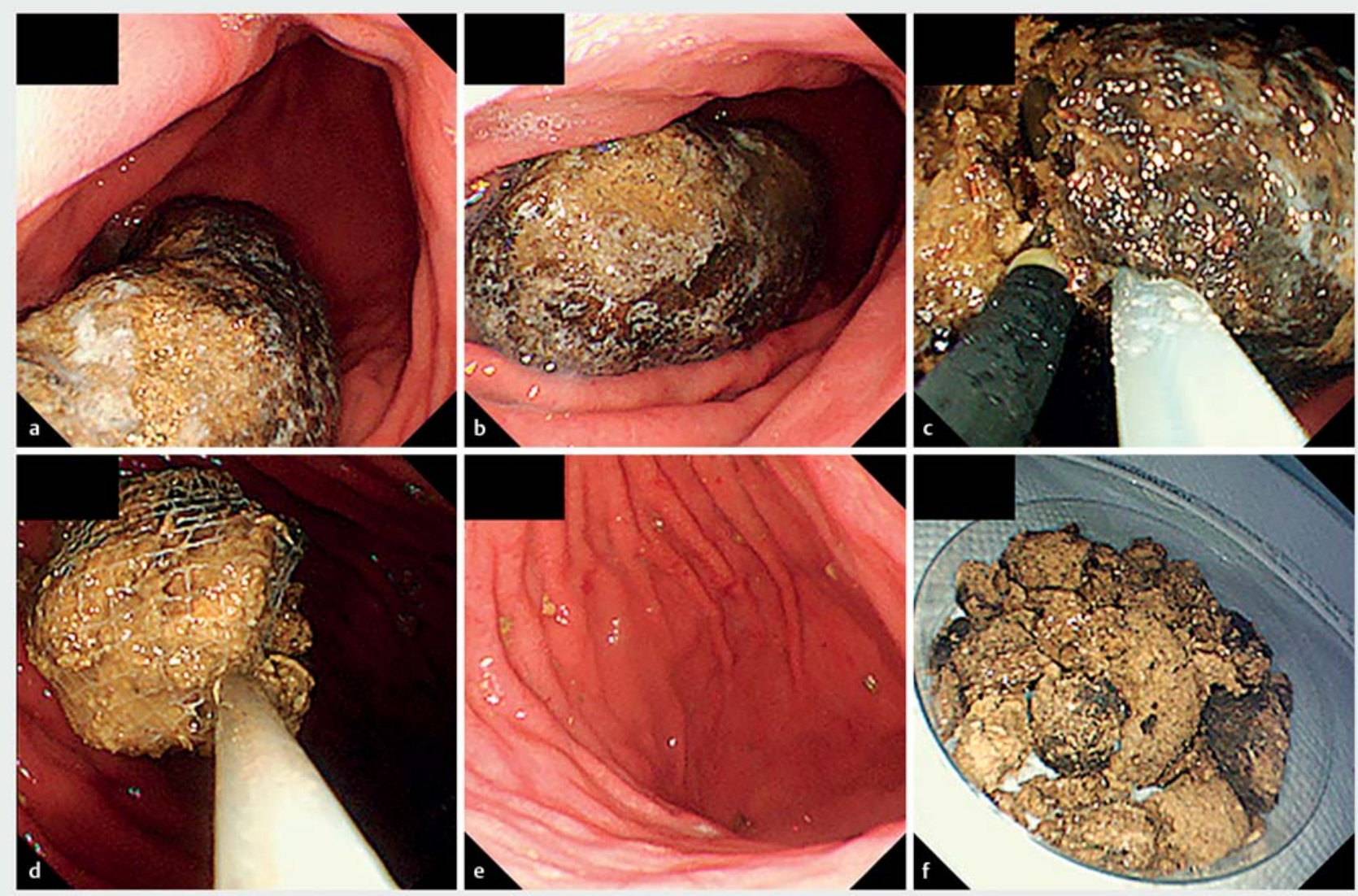

- Fig. 1 Removal of a giant gastric bezoar with the grasp-and-smash technique through a double-channel endoscope. a, b Upper gastroscopy demonstrated a giant ellipsoid-shaped bezoar with hard surface occupying over half of the gastric lumen. $c$ After grasping the short axis of the bezoar by a snare, we smashed it many times with a forceps while pulling a snare toward ourselves to break it into small pieces. $\mathbf{d}, \mathbf{e}, \mathbf{f}$ All pieces of the bezoar were collected with a retrieval net. 


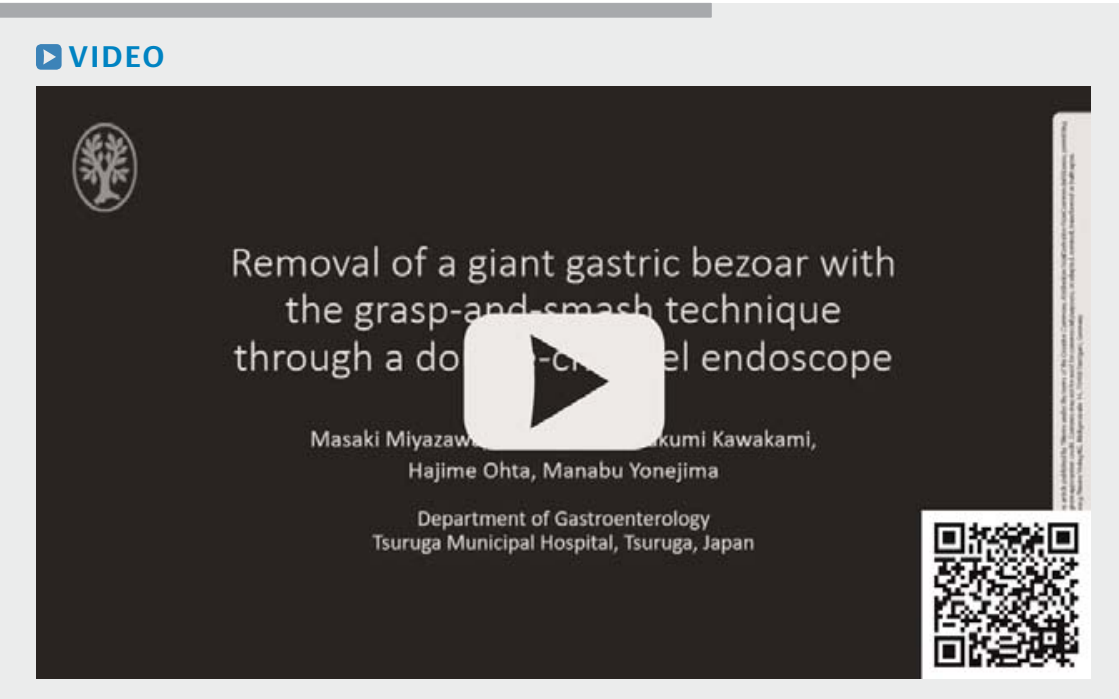

- Video 1 Removal of a giant gastric bezoar with the grasp-and-smash technique through a double-channel endoscope.

ves [3,4] and yttrium aluminum garnet (YAG) laser [5] have been reported. However, our method does not require new and expensive equipment. This treatment can be used safely and easily at any medical institution or by non-experienced endoscopists.

\section{Competing interests}

The authors declare that they have no conflict of interest.
The authors

Masaki Miyazawa, Tatsuo Kumai, Takumi Kawakami, Hajime Ohta, Manabu Yonejima Tsuruga Municipal Hospital, Department of Gastroenterology, Fukui, Japan

\section{Corresponding author}

\section{Masaki Miyazawa}

Tsuruga Municipal Hospital, Department of Gastroenterology, 1-6-60 Mishima-cho, Tsuruga, Fukui, 914-8502, Japan Fax: +81-770-22-6702

miyacchi_1985@yahoo.co.jp

\section{References}

[1] Kurt M, Posul E, Yilmaz B et al. Endoscopic removal of gastric bezoars: An easy technique. Gastrointest Endosc 2014; 80: 895896

[2] Hu X, Zhang R yi, Liu W. A novel endoscopic treatment for giant gastric bezoars: guidewire-based seesaw-type fragmentation using a specific bezoaratom kit. Endoscopy 2020; 52: E146-E147

[3] Tao Z, Yu Y, Zhou X. New application of dual knife: Easier removal of a giant gastric bezoar. Dig Endosc 2019; 31: e62-e63

[4] Huang Z, Cheng F, Wei W. Giant gastric bezoar removal from the stomach using combined dual knife-electric snare treatment: a case report. J Int Med Res 2020; 48: doi:10.1177/0300060520946523

[5] Grande G, Manno M, Zulli C et al. An alternative endoscopic treatment for massive gastric bezoars: Ho:YAG laser fragmentation. Endoscopy 2016; 48: E217

\section{Bibliography}

Endosc Int Open 2021; 09: E925-E926

DOI 10.1055/a-1401-3782

ISSN 2364-3722

(C) 2021. The Author(s).

This is an open access article published by Thieme under the terms of the Creative Commons Attribution-NonDerivativeNonCommercial License, permitting copying and reproduction so long as the original work is given appropriate credit. Contents may not be used for commercial purposes, or adapted, remixed, transformed or built upon. (https:// creativecommons.org/licenses/by-nc-nd/4.0/)

Georg Thieme Verlag KG, Rüdigerstraße 14, 70469 Stuttgart, Germany

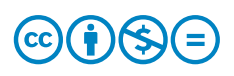

